\title{
Os Efeitos para Uso Policial da Variação da Massa e Velocidade do Projétil na Energia Cinética da Munição e no Recuo da Arma DE FOGO
}

\author{
Giovani Vilnei Rotta
}

Polícia Federal - PR

\section{José Antonio da Silveira Júnior}

Polícia Militar do Paraná

\begin{abstract}
RESUMO
Os métodos internacionalmente utilizados na análise e avaliação de munição para uso policial consideram principalmente os possíveis efeitos causados pelo projétil no alvo, abdicando os efeitos adversos do recuo da arma causados pela munição, como o aumento da dificuldade do controle da arma pelo policial durante uma sequência de disparos. O presente estudo busca preencher tal lacuna propondo a inclusão do fator de potência como uma das variáveis a serem analisadas para a escolha da munição. Para isso, realizou-se um trabalho de dedução matemática a partir de fórmulas e princípios da física clássica para demonstrar o comportamento inter-relacional entre as variáveis massa e velocidade do projétil com o recuo da arma e a energia cinética do projétil.

Os resultados demonstraram que o fator de potência é uma forma eficiente de medir o nível de recuo da arma causado pela deflagração de uma determinada munição e pode ser utilizado como um dos critérios para escolha da munição para uso policial.

Por fim, um estudo de caso também é apresentado utilizando dados balísticos de diversas munições fabricadas pela CBC nos calibres $9 \mathrm{~mm}$ Luger, 40 S\&W e .45 Auto para demonstração da aplicabilidade do fator de potência.
\end{abstract}

Palavras-Chave: Munição. Recuo da arma. Energia cinética. Fator de Potência. Leis de Newton. 


\section{INTRODUÇÃo}

A arma de fogo é um importante instrumento utilizado pelos policiais na sua autodefesa, por vezes sendo o último recurso para garantia de sua sobrevivência em confronto com criminosos. Importante então que a arma do policial seja capaz, quando for necessário o uso em legítima defesa, de realizar disparos que tenham eficácia na neutralização da ameaça.

Wood (2019) relata que até o início da década de 90 não havia um protocolo aceito para avaliar o desempenho balístico terminal das munições para armas de porte utilizadas pelas forças policiais. Então, entre os anos de 1970 e 1990, diversas instituições norte-americanas, tais como National Institute of Justice, US Secret Service, US Navy, US Immigration and Naturalization Service, desenvolveram diversos estudos buscando seus próprios protocolos e padrões de testes balísticos. O resultado foi o surgimento de testes incompatíveis entre si trazendo variáveis, suposições e teorias que tornavam as comparações diretas dos dados infrutíferas.

Nesse contexto que, em dezembro de 1998, o Federal Bureau of Investigation - FBI introduziu seus próprios protocolos para avaliar a performance de balística terminal. Segundo Wood (2019) o protocolo foi amplamente aceito pelas entidades de aplicação da lei e de manufatura, estabelecendo uma linguagem comum, um processo de testes padronizados e benchmarks padronizados para desempenho que permitiram que uma variedade de agências, empresas e indivíduos diferentes conduzissem seus próprios testes e contribuíssem com dados que são diretamente comparáveis aos dados derivados de outros testes e origens.

Atualmente existem diversos protocolos de teste de munição do FBI que consistem em avaliar, entre outros critérios, principalmente a profundidade de penetração do projétil em um bloco de gelatina balística padronizada ao ser disparado a uma distância predefinida. Para cada teste, é utilizado um tipo de barreira diferente acoplado à frente da gelatina balística (sem barreira; roupa pesada e sem barreira; roupa leve e aço; roupa leve e gesso; roupa leve e madeira compensada 
ou; roupa leve e vidro automotivo) os quais são usualmente realizados em laboratórios particulares independentes (BROWN, 2021). O conjunto de resultados dos testes indicariam, portanto, a adequação ou não do cartucho específico para a ampla gama de condições em que os policiais se envolvem em tiroteios. Projéteis que não conseguem penetrar a gelatina balística em 12" ou ultrapassam 18 " são penalizadas. Os projéteis que se expandem e penetram entre 12" e 18" de gelatina são geralmente considerados aceitáveis. Existe uma fórmula complexa para analisar o desempenho da munição, cujo detalhes estão além do escopo deste artigo.

Os protocolos do FBI foram utilizados como um norte pela indústria armamentista para o desenvolvimento de munições para as forças policiais e são até hoje adotados pelo FBI e demais forças policiais norte-americanas na avaliação comparativa entre munições.

Posteriormente, o conceito de poder de parada (stopping power) instituído pelas pesquisas de Marshall \& Sanow (1992) foi utilizado como um referencial para medição da eficácia das munições. Em resumo, o poder de parada de um calibre de munição seria representado pelo percentual de casos em que o combatente foi incapacitado com apenas um tiro a partir de dados estatísticos obtidos de confrontos reais.

De acordo com Oliveira et al (2001) o trabalho mostrou que os projéteis mais leves e mais velozes têm um poder de parada maior do que os mais pesados, mesmo quando esses têm a mesma configuração (ponta oca, por exemplo).

Ellifritz (2011), quando da análise das tabelas de stopping power elaboradas por Marshall E Sanow (1992), estabeleceu diversas críticas, tais como pessoas que uma vez alvejadas independentemente do calibre ou munição, imediatamente cessam a sua atividade contra o policial. Provavelmente as pessoas não sejam fisicamente incapacitadas pelo disparo, mas simplesmente não querem levar outro tiro e desistem.

Ainda, Ellifritz (2011) criticou que o estudo de Marshal \& Sanow (1992) não considerou que os policiais, para se defenderem, 
podem ter que efetuar disparos através de obstáculos, necessitando assim de armas e munições também efetivas para tais situações. Nesse caso, ele considera mais vantajoso o uso de calibres maiores ou mais poderosos.

Outro indicador utilizado na predição da eficácia da munição para neutralizar um indivíduo é a sua energia cinética. Carlucci e Jacobson (2018) relatam que uma das teorias de incapacitação humana por impacto de projétil de arma de fogo é a teoria da deposição da energia cinética (kinetic energy deposition theory). Quanto mais energia cinética for depositada - ou transferida - para o alvo vivo, maior a propensão de danos causados por laceração dos tecidos seguido de sangramento, além de disrupção tecidual e esmagamento. Se o projétil parar dentro do corpo alvejado, então toda a sua energia cinética terá sido nele depositada.

Pela teoria da deposição da energia, calibres mais potentes, como $9 \mathrm{~mm}$ Parabellum, .40 S\&W ou .45 Auto, normalmente teriam mais eficácia em relação aos calibres com menor potencial ofensivo, como .32 S\&WL, 38 SPL ou .380 Auto, por proporcionarem maior energia cinética no projétil expelido pela arma. Porém, normalmente os calibres dito mais potentes podem resultar em maiores recuos da arma causando importantes efeitos adversos à execução do disparo pelo policial, como por exemplo: a) aumento da dificuldade de controle do recuo da arma e assim acrescentando mais tempo para o realinhamento das miras a fim de realizar um eventual segundo disparo; b) receio psicológico pelo forte recuo, antecipando-o no momento do disparo através de contração involuntária da musculatura que acaba por afetar o alinhamento das miras com o alvo durante o acionamento do gatilho, comprometendo o acerto do disparo no alvo.

Os principais métodos descritos e já utilizados internacionalmente para avaliar munições para uso policial (protocolos do FBI, poder de parada e teoria da deposição da energia cinética) são praticamente baseados nos efeitos observados no que o projétil causa no alvo. Porém, eles não englobam os efeitos que a munição causa no recuo da arma, estes também tão importantes e que por vezes são negligenciados ou tratados em um plano secundário. Nada adianta uma munição extremamente eficaz na neutralização do agressor se o recuo que 
a munição gera na arma é tão forte que dificulta em muito o policial a acertar no alvo com uma sequência adequada de disparos. Ou seja, não há eficácia da munição sem acerto no alvo.

Portanto, percebe-se a necessidade de avanços para que também sejam incorporados nos métodos de avaliação e escolha da munição para uso policial algum critério objetivo de quantificação dos efeitos da munição no recuo da arma.

Por fim, ressalta-se que praticamente inexiste literatura científica nacional sobre o tema, cuja única referência bibliográfica encontrada pelos autores foi a de Oliveira et al (2001).

\section{Objetivo do Trabalho}

O presente trabalho busca implementar melhoria nos métodos de análise e seleção de munições para uso policial através da inclusão de variável que considere o nível de recuo da arma causado pela deflagração da munição subsidiando assim a Administração Pública nos processos de aquisição de munições disponíveis no mercado nacional para os órgãos policiais.

\section{Metodologia}

O presente trabalho utiliza conceitos e equações originárias das Leis de Newton, amplamente conhecidas nos livros didáticos de Física, como o de Resnick \& Halliday (1984), para compreender pelo método dedutivo os efeitos da variação da massa, velocidade e energia cinética do projétil no recuo da arma.

Por fim, é apresentada a aplicação do presente estudo utilizando conhecidos dados balísticos das principais munições de calibre 9 $\mathrm{mm}$ Luger, $.40 \mathrm{~S} \& \mathrm{~W}$ e .45 Auto fabricadas pela Companhia Brasileira de Cartuchos - CBC, principal fornecedora de munições para as polícias brasileiras. 


\section{Referencial Teórico}

De uma forma simplificada, o disparo de uma arma de fogo se inicia com a deflagração controlada de uma munição que se encontra alojada na câmara de uma arma. As fagulhas quentes oriundas da deflagração da espoleta por percussão provocam a queima da pólvora da munição, gerando gases e calor. $\mathrm{O}$ calor advindo da reação química exotérmica da queima da pólvora faz com que os gases existentes e gerados no interior da munição se expandam, aumentando em muito a pressão no interior do cartucho. Tais pressões internas do cartucho são então resistidas pelas paredes da câmara e pela culatra do ferrolho da arma obrigando que o alívio da pressão ocorra com a movimentação do projétil pelo cano da arma.

Inicialmente as pressões na câmara crescem com a queima da pólvora até atingir o seu pico máximo, quando então conseguem vencer a inércia do projétil. Nesse momento, o projétil passa a se deslocar até sair pelo cano da arma com determinada velocidade e energia cinética, aliviando assim as pressões dos gases no interior do cano.

O lançamento do projétil traz como consequência o surgimento de forças contrárias de recuo na arma. Porém, os gases gerados pela combustão da pólvora e expandidos pelo calor da reação química também saem pelo cano junto com o projétil e igualmente provocam forças de recuo na arma.

As forças de atrito dinâmico geradas pelo deslocamento do projétil no cano normalmente são bastante pequenas (CARLUCCI; JACOBSON, 2008), mas geram forças de rotação tanto para o projétil como para a arma. Porém, tais forças de rotação não impactam no recuo da arma.

O projétil e o cano se movem simultaneamente em direções opostas durante o disparo. Armas que em seu projeto restringem o movimento do cano, como em revólveres, normalmente transferem suas forças de recuo diretamente ao atirador, o qual terá de suportá-las para evitar que a arma se desloque para trás. Já em pistolas a movimentação do conjunto cano/ferrolho, é parcialmente restringida por uma mola recuperadora que tem a função de reposicionar o conjunto em sua po- 
sição original com a inserção de uma nova munição na câmara para um novo disparo. Essa mola ajuda inicialmente a amortecer o recuo do conjunto cano/ferrolho atrasando a transferência das forças de recuo para o atirador.

As forças dos gases atuam no eixo do cano e não são colineares com o centro de massa das partes que irão suportar o movimento de recuo. Isso gera um par assimétrico de momento de forças (moment couple) que faz com que a arma "pule" durante o disparo. Quanto maior a distância entre o alinhamento do cano e o centro de massa, maior é o "pulo" da arma. Esse fenômeno é chamado como "powder couple" (CARLUCCI; JACOBSON, 2018).

Percebe-se assim um complexo mecanismo de transferência de forças de recuo da arma a serem suportadas pelo atirador durante o disparo, que variam conforme o tipo e projeto da arma utilizada. Porém, as características da munição apresentam papel preponderante no recuo da arma.

Portanto, a fim de compreender como se inter-relacionam o poder ofensivo de uma munição e as suas respectivas forças de recuo geradas pela saída do projétil e dos gases pelo cano da arma durante o disparo, existe a necessidade do entendimento de diversos conceitos da física clássica, tais como energia cinética, força, momento linear, conservação do momento linear e impulso, os quais são abordados a seguir.

\subsection{ENERgia CINÉTICA}

A energia cinética do projétil é um dos parâmetros que se relaciona com o potencial ofensivo da munição, ou seja, é essa a energia máxima que o projétil consegue transferir ao alvo quando impactá-lo. Ela é medida através da equação (1), onde $\mathrm{E}_{\mathrm{c}}$ é a energia cinética (em Joules), $\mathrm{m}_{\mathrm{p}}$ é a massa do projétil (em quilogramas) e $\mathrm{v}_{\text {muzzle }}$ é a velocidade do projétil (em metros por segundo) na saída da boca do cano:

$$
E_{c}=\frac{m_{p} \times v_{\text {muzzle }}^{2}}{2}
$$


Cabe lembrar que essa medição de energia é feita na saída do projétil na boca do cano, momento em que seu valor é máximo. Após o projétil ser expelido do cano, a energia cinética diminui gradativamente em virtude da queda da velocidade do projétil ao longo de sua trajetória ocasionada pelo seu atrito com o ar, comprovado pelas tabelas balísticas fornecidas por diversos fabricantes de munições (FEDERAL AMMUNITION, 2020). Portanto, alvos mais próximos receberão um impacto ou uma energia maior do projétil do que alvos posicionados a longas distâncias.

A energia cinética é inclusive utilizada pela legislação brasileira (Lei n. ${ }^{\circ}$ 10.826/2003 e Decretos n. ${ }^{\circ} 9.847 / 2019$ e 10.030/2019) para classificar as armas e suas munições como de uso permitido (aquelas que são permitidas para o uso das pessoas em geral, desde que atendam determinados requisitos legais) ou de uso restrito (cuja utilização é permitida somente a determinadas instituições definidas em lei, como forças policiais entre outras).

\subsection{MOMENTO LiNeAR}

A Terceira lei de Newton diz que "a cada ação sempre se opõe uma reação igual, ou seja, as ações mútuas de dois corpos, um sobre o outro, são sempre iguais e dirigidas para partes contrárias" (RESNICK; HALLIDAY,1984). É a famosa lei da ação e reação, ou seja, quando a arma expele projétil e gases com determinadas massas e respectivas velocidades imprimidas pela força de expansão dos gases durante a queima da pólvora, haverá sempre uma força de reação em sentido contrário aplicada no cano da arma. Essas forças de ação e de reação são medidas multiplicando a massa do corpo pela variação da sua velocidade em determinado tempo (equivalente à aceleração imposta pela força no corpo), chegando à expressão da Segunda lei de Newton apresentada na equação (2), onde "a força resultante que atua sobre um corpo é proporcional ao produto da massa pela aceleração por ele adquirida" (RESNICK; HALLIDAY, 1984):

$$
F=m \times a=m \times \frac{d v}{d t}=\frac{d m v}{d t}
$$


Aqui $F$ é força, $m$ é massa, $a$ é aceleração, $d v$ é a variação de velocidade, e $d t$ é a variação de tempo.

$\mathrm{Na}$ época, Newton expressou a força como a variação do produto "massa x velocidade" ao longo do tempo e chamou tal expressão "massa x velocidade" como quantidade de movimento, atualmente denominada como momento linear, conforme a equação (3), onde $M$ é o momento linear, $m$ é massa e $v$ é velocidade.

$$
M=m \times v
$$

O momento linear está diretamente associado pela equação (2) com as forças de ação e reação. Portanto, quanto maiores os momentos lineares do projétil e dos gases (forças de ação), consequentemente maiores serão as forças aplicadas no recuo da arma (forças de reação) em sentido contrário.

Um exemplo prático da aplicação desse conceito é visto nas modalidades desportivas de Tiro Prático, esporte regulamentado internacionalmente pela International Practical Shooting Confederation - IPSC e praticado inclusive por policiais de diversos países. A IPSC (2019) aplica em seu conjunto de regras a obrigatoriedade do uso de munições com um fator de potência mínimo (Power Factor), calculado através da equação (4), de forma a garantir igualdade nas munições utilizadas entre seus competidores.

$$
P F_{p}=\frac{m_{p} \times v_{\text {muzzle }}}{1000}
$$

Aqui $P F_{p}$ éo fator de potência definido pela IPSC, $m_{p}$ é a massa do projétil em grains, e $v_{\text {muzzle }}$ é a velocidade do projétil em pés por segundo medido na saída do cano.

Ao invés de colocar em igualdade o potencial ofensivo das munições dos atiradores, no sentido de todos terem munições com o mesmo potencial para derrubar um alvo metálico (mesma energia cinéti$\mathrm{ca})$, a IPSC preferiu que houvesse uma igualdade no momento linear do projétil (como será demonstrado na seção 4.3). O objetivo é buscar a igualdade entre as munições dos competidores em relação ao recuo da arma (forças de reação) durante a competição. 
O fator de potência utilizado pela IPSC é um parâmetro usado para medir o nível de recuo da arma causado pela saída do projétil na deflagração da munição, sendo que quanto maior o fator de potência, maior o recuo da arma; e quanto maior o recuo, maior a dificuldade de retomada do controle da arma para realização de um segundo disparo.

Comparando as equações (1) e (4) percebe-se que o fator de potência da munição não mede a sua energia cinética, visto que são grandezas diferentes - a velocidade é elevada ao quadrado na equação (1). Porém, pode-se utilizar munições que possuam mesmo fator de potência (nível de recuo) com energias cinéticas diferentes. Por exemplo, uma munição com massa $m$ e velocidade $v$ e outra munição com metade dessa massa, mas com o dobro de velocidade, obtém-se o mesmo fator de potência para ambas as munições; porém, a energia cinética da segunda será o dobro da primeira. Isso porque a energia cinética aumenta ao quadrado com a velocidade. O sentido físico disso é que a munição com maior energia cinética terá uma maior capacidade para neutralizar uma pessoa alvejada, já que o projétil pode transferir a esta pessoa uma maior quantidade de energia. Ao contrário, utilizando-se uma munição com o dobro da massa, mas com a metade da velocidade, esta terá pelo mesmo motivo a metade de energia cinética que a da munição com projétil leve e terá mais dificuldade para neutralizar o oponente com um único disparo.

\subsection{CONSERVAÇÃo DO MOMENTO LINEAR}

Outro princípio da Física, o Princípio da conservação do momento linear, determina que "quando a resultante das forças externas que atuam em um sistema é nula, o vetor momento linear do sistema permanece constante" (RESNICK; HALLIDAY, 1984). No caso em voga, o sistema corresponde ao conjunto arma/munição. Como não existe nenhuma aplicação de força externa a esse sistema (não existe algo externo à arma que empurre a munição para fora do cano), a soma do momento lineares $M_{p} \mathrm{e} M_{g}$ (referente aos momentos de ação do projétil e dos gases, respectivamente) e do momento linear $M_{\text {recoil }}$ (reação ou recuo da arma) devem necessariamente se anular, conforme a equação (5): 


$$
M_{\text {recoil }}=M_{p}+M_{g}
$$

Inserindo a equação (3) em (5) com as respectivas massas e velocidades de cada componente, obtém-se a equação (6) onde $m_{p}$ é a massa do projétil, $v_{\text {muzzle }}$ é a velocidade do projétil na saída do cano, $m_{g}$ e $v_{g}$ são respectivamente a massa e velocidade dos gases, $m_{\text {recoil }}$ é a massa de todas as partes da arma que se deslocarão com o recuo, e vrecoil é a velocidade dessas partes da arma que se deslocarão em sentido contrário ao projétil:

$$
m_{\text {recoil }} \times v_{\text {recoil }}=m_{p} \times v_{\text {muzzle }}+m_{g} \times v_{g}
$$

Dividindo a equação (6) por 1.000 em ambos os lados e inserindo nela a equação (4), obtém-se a equação (7), considerando que a massa e velocidade devem ser sempre utilizadas nas unidades grains e pés $/ s$ :

$$
\frac{m_{\text {recoil }} \times v_{\text {recoil }}}{1000}=P F_{p}+\frac{m_{g} \times v_{g}}{1000}
$$

A equação (7) demonstra que o fator de potência $P F_{p}$ definido pela IPSC está diretamente relacionado com a parcela do recuo da arma causado pela saída do projétil da arma, conforme já visto na seção 4.2. Porém, existe outra parcela de recuo oriundo dos gases da queima da pólvora que se somam para determinar o nível de recuo total da arma. Portanto, a equação (7) pode ser reescrita através da equação (8) em termos de fatores de potência, onde $P F_{t}$ é o fator de potência total de recuo, $P F_{p}$ é o fator de potência do projétil definido pela IPSC, e $P F_{g}$ é o fator de potência dos gases:

$$
P F_{t}=P F_{p}+P F_{g}
$$

$\mathrm{O}$ valor do fator de potência $P F_{p}$ é facilmente calculado através da equação (4) multiplicando a massa conhecida do projétil com a medida da sua velocidade na boca do cano obtida por meio do uso de um cronógrafo. Já a obtenção da massa e velocidade dos gases para cálculo do valor de $P F_{g}$ é mais complexa, necessitando a adoção de algumas considerações e simplificações sobre o comportamento dos gases oriundos da queima da pólvora. 
Germershausen et al. (1982) e Carlucci \& Jacobson (2018) dividiram a ação dos gases em duas fases: antes e depois do projétil sair do cano.

No instante imediatamente anterior à saída do cano, o projétil encontra-se em sua velocidade máxima $\left(v_{\text {muzzle }}\right)$ na boca do cano. De forma conservadora, pode-se adotar que toda a massa de gás que se expande em direção à saída do cano também se encontra na mesma velocidade do projétil. Nesse caso, o momento linear dos gases na saída do projétil então é calculado pela equação (9): cano.

$M_{g}=m_{g} \times v_{m u z z l e}$, no instante anterior à saída do projétil do

Importante ressaltar que, por simplificação, nenhum gás escaparia pelo cano ou culatra antes da saída projétil.

Quando o projétil sai do cano, a pressão dos gases cai abruptamente e a velocidade média de saída dos gases será aproximadamente entre 1.200 e $1.400 \mathrm{~m} / \mathrm{s}$, segundo estudos de Germershausen et al. (1982). O mesmo autor recomenda a equação (10) como estimativa das velocidades média dos gases após a saída do projétil, onde $v_{g}$ é a velocidade média dos gases, $v_{m u z z l e}$ é a velocidade do projétil na saída do cano, e $c$ é a velocidade média de propagação do som em gases propelentes (aproximadamente $1.000 \mathrm{~m} / \mathrm{s}$ ou 3.200 pés/s):

$$
v_{g}=\sqrt{v_{\text {muzzle }}^{2}+c^{2}}
$$

Nesse caso, o momento linear dos gases após a saída do projétil pode ser calculado pela equação (11): do cano.

$M_{g}=m_{g} \times \sqrt{\left(v^{2}{ }_{\text {muzzle }}+c^{2}\right)}$, imediatamente após a saída do projétil (11)

Em relação ao valor da massa dos gases, deve-se recorrer à Lei de Lavoisier (Lei da Conservação das Massas) onde a soma total das massas das espécies envolvidas na reação (reagentes) é igual à soma total das massas das substâncias produzidas pela reação (produtos), ou 
seja, em um sistema fechado a massa total permanece constante. Portanto, havendo a queima completa da pólvora, a massa de gases gerados na reação química será igual à massa da carga de pólvora da munição. Já a massa de ar preexistente no interior do cartucho e no interior do cano (os quais também serão expelidos pelo cano) pode ser desconsiderada por ser muito menor que a massa de pólvora (CARLUCCI; JACOBSON, 2018).

Importante atentar que a massa de gases gerados se expande em todas as direções, gerando forças que a desloca tanto na direção de lançamento do projétil quanto na direção de recuo das peças da arma. Como não há a aplicação de forças externas, o centro de massa de todo o conjunto deve permanecer inalterado com metade da massa dos gases deslocando-se junto com a arma e a outra metade junto com o projétil. Dessa forma, pode-se calcular $m_{g} \mathrm{e} m_{\text {recoil }}$ através das equações (12) e (13), onde $m_{c}$ é a carga de pólvora utilizada na munição e $m_{\text {gun }}$ é a massa total das partes da arma que se deslocarão com o recuo:

$$
\begin{aligned}
& m_{g}=\frac{m_{c}}{2} \\
& m_{\text {recoil }}=m_{\text {gun }}+\frac{m_{c}}{2}
\end{aligned}
$$

Inserindo a equação (12) nas equações (9) e (11), e estas na equação (6) juntamente com a equação (13), obtém-se as equações gerais (14) a (17) para as parcelas de $M_{\text {recoil }} M_{p}$ e $M_{g}$ da equação (5):

- Para o instante em que o projétil sai do cano:

$$
\left(m_{\text {gun }}+\frac{m_{c}}{2}\right) \times v_{\text {recoil }}=\left(m_{p} \times v_{\text {muzzle }}\right)+\left(\frac{m_{c}}{2} \times v_{\text {muzzle }}\right)
$$

$\mathrm{Ou}:$

$$
M_{\text {recoil }}=\left(m_{p} \times v_{\text {muzzle }}\right)+\left(\frac{m_{c}}{2} \times v_{\text {muzzle }}\right)
$$

- Para o instante após a saída do projétil e dos gases pelo cano: 


$$
\left(m_{\text {gun }}+\frac{m_{c}}{2}\right) \times v_{\text {recoil }}=\left(m_{p} \times v_{\text {muzzle }}\right)+\left(\frac{m_{c}}{2} \times \sqrt{v_{\text {muzzle }}^{2}+c^{2}}\right)
$$

Ou:

$$
M_{\text {recoil }}=\left(m_{p} \times v_{\text {muzzle }}\right)+\left(\frac{m_{c}}{2} \times \sqrt{v_{\text {muzzle }}^{2}+c^{2}}\right)
$$

Comparando as equações (15) e (17) percebe-se que o momento linear dos gases será sempre maior após a saída do projétil do cano, conforme a inequação (18):

$$
v_{\text {muzzle }}<\sqrt{v_{\text {muzzle }}^{2}+c^{2}}
$$

Consequentemente, conforme a equação (5), o momento linear de recuo $M_{\text {recoil }}$ também será máximo logo após a saída do projétil pelo cano, já que o valor do momento linear do projétil é o mesmo tanto no instante anterior à saída do cano quanto no instante imediatamente posterior à sua saída. Isso decorre do acréscimo de força pela saída dos gases no cano, como será visto posteriormente. Portanto, a equação (17) é a de maior interesse nesse estudo, pois fornece o máximo momento linear de recuo da arma causado pela deflagração de determinada munição.

A equação (17) pode também ser expressa em termos de fator de potência, seguindo a equação (8), ao se dividir por 1.000 ambos os lados da equação, lembrando sempre de utilizar nesse caso as unidades grains e pés/s para massa e velocidade, conforme a equação (19):

$$
P F_{t}=\left(\frac{m_{p} \times v_{m u z z l e}}{1000}\right)+\left(\frac{\frac{m_{c}}{2} \times \sqrt{v_{m u z z l e}^{2}+c^{2}}}{1000}\right)
$$

Inde:

$$
P F_{g}=\left(\frac{\frac{m_{c}}{2} \times \sqrt{v_{m u z z l e}^{2}+c^{2}}}{1000}\right)
$$




\subsection{DeFINIÇÃo DE RECUO}

A deflagração da espoleta e consequente queima da pólvora cria uma força gerada pela expansão dos gases provocando o deslocamento de ambos, projétil e gases, pelo cano da arma. Simultaneamente, gera-se uma força oposta de reação sobre as partes móveis da arma em intensidade suficiente para manterem equilibradas as equações (5) e (14) em termos de velocidades relativas entre projétil, gases e arma conforme as respectivas massas de cada um. Essas velocidades crescem até o projétil sair do cano, momento em que a velocidade e o momento linear do projétil são máximos.

Quando o projétil é expelido do cano, os gases gerados pela queima da pólvora deixam de atuar sobre o projétil, pois suas altas pressões passam a ser dissipadas para a atmosfera, e a velocidade do projétil permanece então constante (aqui o atrito com o ar é desprezado no pequeno deslocamento do projétil após a saída do cano até a completa dissipação dos gases). Não havendo mais aumento de velocidade, ou seja, a aceleração passa a ser nula no projétil, consequentemente não há mais força sendo aplicada nele e o seu momento linear também permanece constante. Porém, ao mesmo tempo em que ocorre a saída do projétil do cano, há também a saída de parte dos gases propulsores, os quais aumentam de velocidade média para níveis inclusive superior ao do próprio projétil por não mais existir uma barreira (o próprio projétil) que antes restringia seu deslocamento. Se há aumento de velocidade dos gases após a saída do projétil, também há aumento do momento linear até que ocorra a completa dissipação da pressão. Somente após a dissipação total das pressões alcança-se o momento linear máximo dos gases que, somado ao momento linear final do projétil, resulta no momento linear máximo obtido pela equação (17).

O mesmo raciocínio se aplica à arma, enquanto há aumento de velocidade do projétil e/ou dos gases, haverá uma força de reação (ou recuo) na arma até que o projétil saia do cano e as pressões dos gases

sejam dissipadas. Portanto, conforme Carlucci \& Jacobson (2018), o recuo é gerado na arma pela reação de suas partes móveis ao impulso da pressão dos gases enquanto o projétil está no cano e enquanto os gases propulsores estão sendo exauridos após a saída do projétil. 
O sentido físico de recuo é o impulso, expresso por ambas as equações (21) e (22), onde $I$ é o impulso, $F$ é a força, $\Delta t$ é o tempo de aplicação da força, e $\Delta M$ é a variação de momento linear:

$$
\mathrm{I}=\mathrm{F} \times \Delta \mathrm{t}
$$

$$
\mathrm{I}=\Delta \mathrm{M}
$$

Ou seja, conforme a equação (22), quanto maior for a variação da soma dos momentos lineares do projétil e dos gases, maior o impulso (ou recuo) da arma. Ou ainda, conforme a equação (21), quanto maior a força e/ou maior o tempo de aplicação dela (tempo necessário para o lançamento do projétil e dissipação dos gases) maior será o impulso (ou recuo) da arma.

Uma forma de representar graficamente o impulso de um disparo de arma de fogo é através da curva típica da variação da pressão dos gases no interior do cano ao longo do tempo, conforme a Figura 1 (GERMERSHAUSEN,1982; CHEVALIER, 2008; CARLUCCI; JACOBSON, 2018). A pressão gerada pela queima da pólvora aumenta com o tempo após a deflagração da espoleta até alcançar um pico de pressão $\left(p_{\text {peak }}\right)$, normalmente antes mesmo de vencer a inércia do projétil (CHEVALIER, 2008). Quando o projétil entra em movimento, a pressão começa a diminuir à medida que a velocidade do projétil cresce e o espaço por trás dele aumenta de volume. Quando o projétil é expelido do cano no tempo $t_{m u z z l e}$, a pressão residual ainda existente é então dissipada até se equalizar com a pressão atmosférica. Germershausen $e t$ al. (1982) e Carlucci \& Jacobson (2018) assumem por simplificação um decaimento linear da pressão entre o momento da saída do projétil e o tempo $t_{f}$ quando se considera o fim da dissipação dos gases. Por fim, $p_{m}$ representa a pressão média dos gases exercida no interior do cano ao longo de todo o tempo $t_{f}$ 


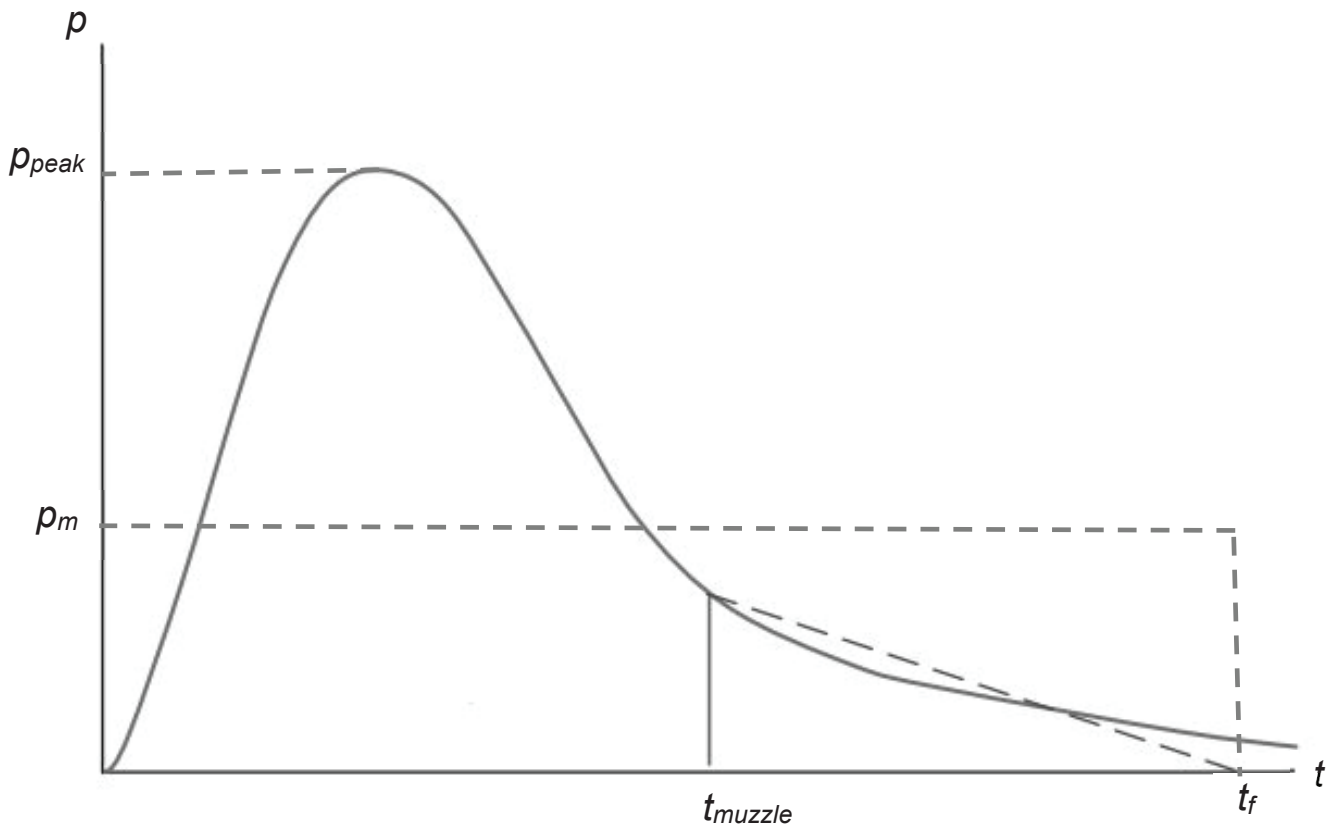

Figura 1: Típica curva pressão-tempo que ocorre no cano durante o disparo.

A força exercida pela pressão dos gases pode ser expressa pela equação (23), onde $p$ é a pressão dos gases e $A$ é a área da seção transversal do cano (ou a área da base do projétil):

$$
F=\frac{p}{A}
$$

Inserindo a equação (23) na equação (21) obtém-se:

$$
I=\frac{p \times \Delta t}{A}
$$

A equação (24) demonstra que o impulso total provocado pelos gases é representado pela área existente abaixo da curva da Figura 1 dividido pela área da seção transversal do cano (ou a área da base do projétil). Portanto, pela Lei de Conservação do momento linear, o mesmo impulso gerado para expelir o projétil e gases pelo cano também é dado à arma no sentido contrário. Ou seja, a área delimitada pela curva da Figura 1 dividida pela área da seção transversal do projétil também representa o recuo total da arma $I_{\text {recoil }}$ expresso pela equação (25): 


$$
I_{\text {recoil }}=\frac{p_{m} \times t_{f}}{A}
$$

Outra forma de representar graficamente o impulso (ou recuo) é através da variação do momento linear no tempo, conforme a Figura 2.

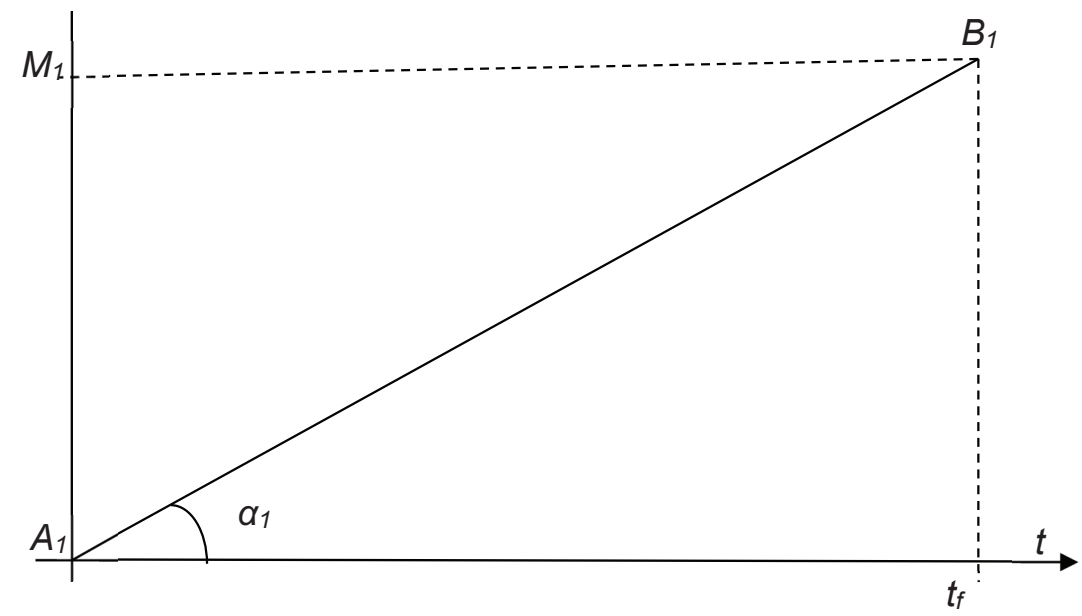

Figura 2: Variação do momento linear referente à força de recuo da arma.

O gráfico da Figura 2 apresenta a variação da soma $M$ dos momentos lineares do projétil e dos gases durante um disparo de munição ao longo do tempo $t$. No tempo $t=0$ a munição não se encontra deflagrada e, portanto, sem qualquer movimento. Se não há movimento, a velocidade é zero e o resultado do momento linear é nulo antes do disparo. Esse estágio é representado pelo ponto $A_{1}$ do gráfico. Quando a munição é deflagrada o projétil e os gases passam então a se movimentar e a adquirir velocidade, a qual aumenta ao longo do tempo. Aumentando a velocidade há também um aumento da soma dos momentos lineares do projétil e dos gases, resultado da soma das multiplicações das massas pelas suas respectivas velocidades [ver equação (6)]. Esse aumento do momento linear é representado simplificadamente pela reta entre os pontos $A_{1}$ e $B_{1}$, cujo valor máximo é obtido após a dissipação da pressão dos gases com a saída do projétil do cano (ponto $B_{1}$ ), calculado através da equação (17), o qual ocorre num intervalo de tempo $t_{f}$

Igualando as equações (21) e (22), obtém-se a equação (26): 


$$
F=\frac{\Delta M}{\Delta t}=\frac{M_{1}}{t_{f}}
$$

$\mathrm{Ou}:$

$$
F=\tan \alpha_{1}
$$

Demonstra-se, assim, que a reta $\mathrm{A}_{1} \mathrm{~B}_{1}$ com inclinação $\alpha_{1}$ do gráfico da Figura 2 representa a força média aplicada pelos gases entre o início da deflagração da munição e o tempo $t_{f}$ (momento da completa exaustão dos gases do cano após a saída do projétil). A força média dos gases também se encontra representada na Figura 1 dividindo-se $p_{m}$ pela área da seção transversal do cano (ou a área da base do projétil).

Já o impulso total é representado pela variação total do momento linear $M$ na Figura 2, de acordo com a equação (22), e equivale ao valor $M_{l}$.

Como os momentos lineares da arma e do projétil/gases precisam ser de mesmo valor em qualquer tempo (princípio da conservação do momento linear), o mesmo gráfico da Figura 2 se aplica para a arma. Portanto, o impulso calculado pela multiplicação da força $F$ pelo período $t_{f}$ é o recuo total da arma - equação (21), o qual também pode ser representado pela variação total $M_{1}$ do momento linear - equação (22).

Sabendo que o recuo se refere à variação do momento linear (ou impulso), o seu valor máximo gerado no disparo pode ser calculado através da equação (17), ou através da equação (19) se desejado o cálculo em termos de fator de potência total.

Observa-se, conforme as equações (17) e (19), que o valor do recuo depende somente de variáveis que expressam características exclusivas da munição, as quais são: massa do projétil, velocidade do projétil e massa da carga de pólvora. Isso permite comparar o potencial de recuo entre munições de diversos tipos e calibres, desde que realizados os testes em provetes padronizados, eliminando a interferência de variáveis características das armas, como comprimento do cano, massa da arma, sistema de recuo, centro de massa da arma, entre outros. 
Por fim, importante destacar que ao ter duas munições distintas que, ao serem disparadas, apresentam a mesma variação de momento linear de recuo $M_{\text {recoil }}$ (ou o fator de potência total $P F_{t}$ ) obtidos pelas equações (17) ou (19), então ambas as munições causarão o mesmo nível de recuo quando atiradas pela mesma arma independentemente de suas diferenças em termos de carga de pólvora $\left(m_{c}\right)$, massa do projétil $\left(m_{p}\right)$ e velocidade do projétil $\left(v_{p}\right)$. Uma munição só causará um maior recuo em relação à outra na mesma arma se aquela apresentar maior variação do momento linear (ou fator de potência total) durante o disparo.

\subsection{RELEVÂNCIA DO MOMENTO LINEAR DOS GASES NO RE- CUO TOTAL DA ARMA}

Importante neste estudo é avaliar o quão significativo é a parcela do momento linear dos gases $\left(M_{g}\right)$ no cálculo do momento linear de recuo $\left(M_{\text {recoil }}\right)$. Para isso, buscou-se calculá-los para os principais tipos de munições fabricadas pela Companhia Brasileira de Cartuchos - CBC nos calibres $9 \mathrm{~mm}$ Luger, $.40 \mathrm{~S} \& \mathrm{~W}$ e .45 Auto, os quais são os calibres mais comuns das pistolas utilizadas pelas forças policiais brasileiras.

Os dados de massa do projétil e sua velocidade na boca do cano para cada uma das suas munições encontram-se divulgados no site da CBC (2020) na internet. São dados extremamente úteis fornecidos pelo fabricante através de testes padronizados que auxiliam o consumidor a definir a munição ideal para a finalidade que se deseja. Tais dados encontram-se descritos na Tabela 01 .

Porém, a carga de pólvora de cada tipo de munição não é divulgada pela $\mathrm{CBC}$, fato que dificulta a realização dos cálculos necessários para obtenção de $M_{g}$. Ressalta-se que a maioria dos fabricantes internacionais de muniçôes também não divulgam essa informação em suas páginas na internet. A fim de suprir essa carência, adotou-se o valor médio da massa de pólvora recomendada pela $\mathrm{CBC}$ para uso de suas pólvoras quando vendidas para realização de recarga de munições, ou seja, 6,35 gr para o calibre $9 \mathrm{~mm}$ Luger, 7,15 gr para o calibre $.40 \mathrm{~S} \& \mathrm{~W}$ e 5,1 gr para o calibre .45 Auto. Os dados, fórmulas utilizadas e resultados obtidos encontram-se indicados na Tabela 01 . 
Os resultados da Tabela 01 mostram que o recuo gerado pela dissipação dos gases representa em torno de $4 \%$ a $8 \%$ do recuo total da arma. Em termos absoluto ele é significativo e precisa ser considerado no projeto da arma em si, a fim de que suas peças sejam adequadamente dimensionadas para resistir às forças geradas.

Porém, no caso de comparação entre munições diferentes, percebe-se que os gases não influenciam significativamente na análise da diferença de recuos totais, podendo inclusive serem negligenciados. Por exemplo, se fosse desconsiderada a parcela do recuo dos gases no cálculo da munição \#9 e da munição \#17 da Tabela 01 (que são as munições de maior e de menor parcela dos gases no recuo total e ao mesmo tempo a de maior e menor $P F_{t}$ ) ter-se-ia uma diferença de fator de $84,6 \times 10^{-3} \mathrm{gr} \cdot \mathrm{pés} / \mathrm{s}$ (diferença entre os fatores da munição) em vez de $83,4 \times 10^{-3} \mathrm{gr} \cdot$ pés/s (diferença entre os fatores totais considerando também o recuo provocado pelos gases). Isso representa um erro de 1,4\% na estimativa da variação de recuo entre as duas munições, o que pode ser negligenciado.

Tabela 01: Principais munições fabricadas pela CBC nos calibres $9 \mathrm{~mm}$ Luger, . 40 S\&W e .45 Auto.

\begin{tabular}{|c|c|c|c|c|c|c|c|c|c|c|}
\hline & \multirow{3}{*}{ Munição } & \multicolumn{9}{|c|}{ Equação utilizada } \\
\hline & & - & - & $(4)$ & (1) & - & (10) & $(20)$ & $(8)$ & - \\
\hline & & $\begin{array}{l}\mathrm{m}_{\mathrm{p}} \\
(\mathrm{gr})\end{array}$ & $\begin{array}{c}\mathbf{v}_{\text {muzle }} \\
(\text { pés/s) }\end{array}$ & $\mathbf{P F}_{\mathrm{p}}$ & $\operatorname{Ec}(J)$ & $\mathbf{m}_{\mathrm{c}}(\mathrm{gr})$ & $\begin{array}{c}\mathbf{v}_{\mathbf{g}} \\
\text { (pés/s) }\end{array}$ & $\mathrm{PF}_{\mathrm{g}}$ & $\mathrm{PF}_{\mathrm{t}}$ & $\begin{array}{l}\mathrm{PF}_{\mathrm{g}} \\
\mathrm{PF}_{\mathrm{t}} \\
(\%)\end{array}$ \\
\hline 1 & $\begin{array}{l}9 \mathrm{MM} \text { EXPO } \\
+\mathrm{P}+\mathrm{BON}- \\
\text { DED } 115 \mathrm{GR}\end{array}$ & 115 & 1.329 & 152,8 & 611 & 6,35 & 3.465 & 11,0 & 163,8 & 6,7 \\
\hline 2 & $\begin{array}{c}\text { 9MM EXPO } \\
+ \text { P SUB- } \\
\text { SÔNICO } \\
\text { BONDED } \\
147 \mathrm{GR} \\
\end{array}$ & 147 & 1.050 & 154,4 & 488 & 6,35 & 3.368 & 10,7 & 165,0 & 6,5 \\
\hline 3 & $\begin{array}{c}9 \mathrm{MM} \text { EXPO } \\
+\mathrm{P}+\mathrm{BON}- \\
\text { DED } 124 \mathrm{GR}\end{array}$ & 124 & 1.215 & 150,7 & 551 & 6,35 & 3.423 & 10,9 & 161,5 & 6,7 \\
\hline 4 & $\begin{array}{l}\text { 9MM EXPO } \\
+\mathrm{P}+\mathrm{GOLD} \\
\text { HEX 115GR }\end{array}$ & 115 & 1.246 & 143,3 & 537 & 6,35 & 3.434 & 10,9 & 154,2 & 7,1 \\
\hline
\end{tabular}


Os efeitos para uso policial da variação da massa e velocidade do projétil na energia cinética...

\begin{tabular}{|c|c|c|c|c|c|c|c|c|c|c|}
\hline 5 & $\begin{array}{c}\text { 9MM } \\
\text { CXPO +P+ } \\
\text { COPPER } \\
\text { BULLET } \\
\text { TACTICAL }\end{array}$ & 93 & 1.427 & 132,7 & 570 & 6,35 & 3.504 & 11,1 & 143,8 & 7,7 \\
\hline 6 & $\begin{array}{c}9 \mathrm{MM} \mathrm{NTA} \\
124 \mathrm{GR}\end{array}$ & 124 & 1.109 & 137,5 & 459 & 6,35 & 3.387 & 10,8 & 148,3 & 7,3 \\
\hline 7 & $\begin{array}{c}9 \mathrm{MM} \text { EXPO } \\
115 \mathrm{GR}\end{array}$ & 115 & 1.155 & 132,8 & 462 & 6,35 & 3.402 & 10,8 & 143,6 & 7,5 \\
\hline 8 & $\begin{array}{c}9 \mathrm{MM} \\
\text { (ETOG, } \\
\text { CHOG } \\
\text { TREINA ou } \\
\text { NTA) 124GR }\end{array}$ & 124 & 1.109 & 137,5 & 459 & 6,35 & 3.387 & 10,8 & 148,3 & 7,3 \\
\hline 9 & $\begin{array}{c}\text { 9MM EXPP } \\
\text { 95GR }\end{array}$ & 95 & 1.345 & 127,8 & 517 & 6,35 & 3.471 & 11,0 & 138,8 & 7,9 \\
\hline 10 & $\begin{array}{c}.40 \text { S\&W } \\
\text { EXPO } \\
\text { GOLD HEX } \\
155 \mathrm{GR}\end{array}$ & 155 & 1.205 & 186,8 & 677 & 7,15 & 3.419 & 12,2 & 199,0 & 6,1 \\
\hline 11 & $\begin{array}{c}.40 \text { S\&W } \\
\text { CXPO } \\
\text { COPPER } \\
\text { BULLET } \\
\text { TACTICAL }\end{array}$ & 130 & 1.280 & 166,4 & 641 & 7,15 & 3.447 & 12,3 & 178,7 & 6,9 \\
\hline 12 & $\begin{array}{c}.40 \text { S\&W } \\
\text { (CHPP, } \\
\text { TREINA } \\
\text { ou CSCV) } \\
160 \mathrm{GR} \\
\end{array}$ & 160 & 1.165 & 186,4 & 654 & 7,15 & 3.405 & 12,2 & 198,6 & 6,1 \\
\hline 13 & $\begin{array}{c}.40 \text { S\&W } \\
\text { (NTA ou } \\
\text { ETPP) } \\
180 \mathrm{GR} \\
\end{array}$ & 180 & 990 & 178,2 & 531 & 7,15 & 3.350 & 12,0 & 190,2 & 6,3 \\
\hline 14 & $\begin{array}{c}.40 \mathrm{~S} \& \mathrm{~W} \\
\text { FRANGÍVEL } \\
125 \mathrm{GR}\end{array}$ & 125 & 1.181 & 147,6 & 525 & 7,15 & 3.411 & 12,2 & 159,8 & 7,6 \\
\hline 15 & $\begin{array}{c}.40 \mathrm{~S} \& \mathrm{~W} \\
\text { EXPO BON- } \\
\text { DED 155GR }\end{array}$ & 155 & 1.191 & 184,6 & 662 & 7,15 & 3.414 & 12,2 & 196,8 & 6,2 \\
\hline 16 & $\begin{array}{c}.40 \text { S\&W } \\
\text { EXPO } \\
\text { (GOLD ou } \\
\text { BONDED) } \\
180 \mathrm{GR}\end{array}$ & 180 & 1.024 & 184,3 & 568 & 7,15 & 3.360 & 12,0 & 196,3 & 6,1 \\
\hline
\end{tabular}




\begin{tabular}{c|c|c|c|c|c|c|c|c|c|c}
\hline 17 & $\begin{array}{c}.45 \text { AUTO } \\
\text { EXPO +P } \\
\text { GOLD HEX } \\
185 \mathrm{GR}\end{array}$ \\
\hline 18 & 185 & 1.148 & 212,4 & 734 & 5,1 & 3.400 & 9,9 & 222,3 & 4,4 \\
\hline $\begin{array}{c}.45 \text { AUTO } \\
\text { CSCV } \\
200 \mathrm{GR}\end{array}$ & 200 & 950 & 190,0 & 543 & 5,1 & 3.338 & 9,7 & 199,7 & 4,8 \\
\hline 19 & $\begin{array}{c}.45 \text { AUTO } \\
\text { ETOG } \\
230 \mathrm{GR}\end{array}$ \\
\hline $\begin{array}{c}.45 \text { AUTO } \\
+ \text { P COPPER } \\
\text { BULLET } \\
\text { TACTICAL }\end{array}$ & 165 & 1.148 & 189,4 & 655 & 5,1 & 3.400 & 9,9 & 199,3 & 4,9 \\
\hline
\end{tabular}

Obs: $\mathrm{EXPO}=$ projétil expansivo; $\mathrm{BONDED}=$ projétil com encamisamento colado ao chumbo; $\mathrm{CXPO}=$ projétil monobloco de cobre com camada de estanho, expansivo; NTA = projétil ogival, totalmente encamisado; ETOG = projétil ogival encamisado; $\mathrm{CHOG}$ $=$ projétil de chumbo ogival, sem encamisamento; TREINA $=$ munição ogival encamisada para treinamento; $\mathrm{CSCV}=$ projétil de chumbo semi canto vivo; $\mathrm{CHPP}=$ projétil de chumbo ponta plana; $\mathrm{CXPP}=$ projétil expansivo com penetração superior ao EXPO; HEX = projétil expansivo com configuração hexagonal em seu interior; ETPP = projétil ponta plana encamisado; FRANGIVEL = projétil destinado a romper-se ao impacto em superfície dura $;+\mathrm{P} \mathrm{e}+\mathrm{P}+=$ munição com maior pressão que as munições comuns.

Ensaios realizados com munições de calibre $9 \mathrm{~mm}$ Luger e .45 Auto também corroboraram com a conclusão anterior. Utilizou-se nos ensaios munições recarregadas com projéteis de massa média de 146 gr e 132 gr no calibre $9 \mathrm{~mm}$ e projéteis com massa média de 225 gr para o calibre .45 Auto. A massa de cada tipo de projétil foi obtida pela média das pesagens de uma amostra de 20 unidades realizadas em balança eletrônica com precisão de 0,1 gr. Após a definição do peso médio dos projéteis, realizou-se a recarga de lotes de 15 unidades com diferentes cargas de pólvora por lote até encontrar a carga necessária para obter a velocidade do projétil na saída do cano que alcançasse o fator de potência do projétil $\left(F P_{p}\right)$ desejado. Essa velocidade era obtida pela média das medições das unidades do respectivo lote. 
As munições foram disparadas com armas da marca Glock, modelos G17 para o calibre $9 \mathrm{~mm}$ Luger e G21 para o calibre .45 Auto, e as medidas de velocidade do projétil na saída do cano foram obtidas com o uso de um cronógrafo Crony Alpha.

A recarga das munições foi realizada com uma máquina de recarga da marca RCBS, modelo Ammomaster. Os dados dos insumos utilizados na recarga encontram-se descritos na Tabela 02 e os resultados em termos de fatores de potência obtidos são apresentados na Tabela 03.

Tabela 02: Dados das munições recarregadas utilizadas nos ensaios.

\begin{tabular}{|c|c|c|c|c|}
\hline \multirow{2}{*}{\multicolumn{2}{|c|}{$\begin{array}{l}\text { Dados conhecidos } \\
9 \mathrm{~mm} \text { Luger }\end{array}$}} & \multicolumn{3}{|c|}{ Calibre } \\
\hline & & \multirow{2}{*}{$\begin{array}{c}9 \mathrm{~mm} \text { Luger } \\
132,7 \mathrm{gr}\end{array}$} & \multirow{2}{*}{$\begin{array}{l}.45 \text { Auto } \\
145,8 \mathrm{gr}\end{array}$} & \multirow[b]{2}{*}{$224,5 \mathrm{gr}$} \\
\hline \multirow{3}{*}{ Projétil } & Massa média & & & \\
\hline & Desvio padrão & $0,8 \mathrm{gr}$ & $0,7 \mathrm{gr}$ & $2,0 \mathrm{gr}$ \\
\hline & Tipo de projétil & $\begin{array}{c}\text { Chumbo } \\
\text { ogival com } \\
\text { pintura epóxi }\end{array}$ & $\begin{array}{l}\text { Chumbo ogival } \\
\text { com pintura } \\
\text { epóxi }\end{array}$ & $\begin{array}{l}\text { Chumbo ogival } \\
\text { com pintura } \\
\text { epóxi }\end{array}$ \\
\hline \multirow{2}{*}{ Pólvora } & Marca/Tipo & СBC 207 & СВС 207 & CBC 219 \\
\hline & $\mathrm{m}_{\mathrm{c}}$ & $5,8 \mathrm{gr}$ & $5,1 \mathrm{gr}$ & $3,7 \mathrm{gr}$ \\
\hline Espoleta & Marca & $\mathrm{CBC}$ & $\mathrm{CBC}$ & $\mathrm{CBC}$ \\
\hline Estojo & Marca & $\mathrm{CBC}$ & $\mathrm{CBC}$ & $\mathrm{CBC}$ \\
\hline \multirow{2}{*}{$v_{\text {muzzle }}$} & Média & 967,5 pés/s & 880 pés/s & 572,9 pés/s \\
\hline & Desvio padrão & 36,6 pés/s & 63,7 pés/s & 15 pés/s \\
\hline Cano & $\Delta \boldsymbol{S}(\mathrm{em} \mathrm{m})$ & 0,117 & 0,117 & 0,117 \\
\hline
\end{tabular}

Tabela 03: Fatores de potência obtidos das munições recarregadas.

\begin{tabular}{|c|c|c|c|c|}
\hline $\begin{array}{c}\text { Dados calculados } \\
\text { (em }\end{array}$ & Eq. & $\begin{array}{c}\text { 9 mm Luger, } \\
\text { projétil de } \\
\mathbf{1 0 - 3 2 , 7} \mathbf{g r}\end{array}$ & $\begin{array}{c}\mathbf{9} \text { mm Luger, } \\
\text { projétil de } \\
\mathbf{1 4 5 , 8} \mathbf{~ g r}\end{array}$ & $\begin{array}{c}\mathbf{. 4 5} \text { Auto, } \\
\text { projétil de } \\
\mathbf{2 2 4 , 5} \mathbf{~ g r}\end{array}$ \\
\hline$P F_{p}$ & $(4)$ & 128,4 & 128,3 & 128,6 \\
\hline$P F_{g}$ & $(20)$ & 9,7 & 8,4 & 6,0 \\
\hline$P F_{t}$ & $(19)$ & 138,1 & 136,7 & 134,6 \\
\hline$P F_{g} / P F_{t}$ & & $7,0 \%$ & $6,2 \%$ & $4,5 \%$ \\
\hline
\end{tabular}

Novamente a parcela de $P F_{g}$ em relação ao $P F_{t}$ ficou na faixa entre $4 \%$ e $8 \%$ entre as munições testadas. Porém, o erro na estimativa da variação do momento linear total entre as munições ao descon- 
siderar a parcela referente aos gases foi de aproximadamente $\Delta P F_{t}=$ $3,46 \times 10^{-3} \mathrm{gr} \cdot$ pés/s, o que representa menos de $3 \%$ em relação ao $F P_{m}$.

Mostra-se assim que pode ser desconsiderada a parcela dos gases na análise das variações de nível de recuo entre as munições estudadas dos calibres $9 \mathrm{~mm}$ Luger, $.40 \mathrm{~S} \& \mathrm{~W}$ e .45 Auto da CBC. Essa simplificação facilita o estudo, visto que não há dados exatos fornecidos pelos fabricantes sobre as cargas de pólvoras utilizadas nas munições para o cálculo do recuo dos gases gerados, e permite concluir as análises apenas com os comparativos de $P F_{p}$ entre as munições.

\section{Influência no Recuo ao se Utilizar Projétil Leve ou Pesado}

Não raro os policiais perguntam-se se devem optar por um projétil mais pesado (maior massa) ou um mais leve (menor massa) na sua munição. É um questionamento usual, visto a variedade de projéteis disponibilizados pelas indústrias de munições, e que também merece atenção dos consumidores sob o aspecto do potencial de recuo que cada tipo de projétil causa na arma.

Conforme foi visto, na seção 4.5, a parcela do recuo referente ao impulso dos gases após a saída do projétil pode ser desconsiderada na análise comparativa do valor de recuo entre munições dos calibres $9 \mathrm{~mm}$ Luger, .40 S\&W e .45 Auto fabricadas pela CBC. Adotando essa simplificação, pode-se recorrer ao gráfico da variação do momento linear com o tempo (Figura 3) considerando apenas a variação dos momentos lineares durante o percurso do projétil no cano da arma, mas agora para dois tipos de munição: um com projétil leve e outro com projétil pesado. 


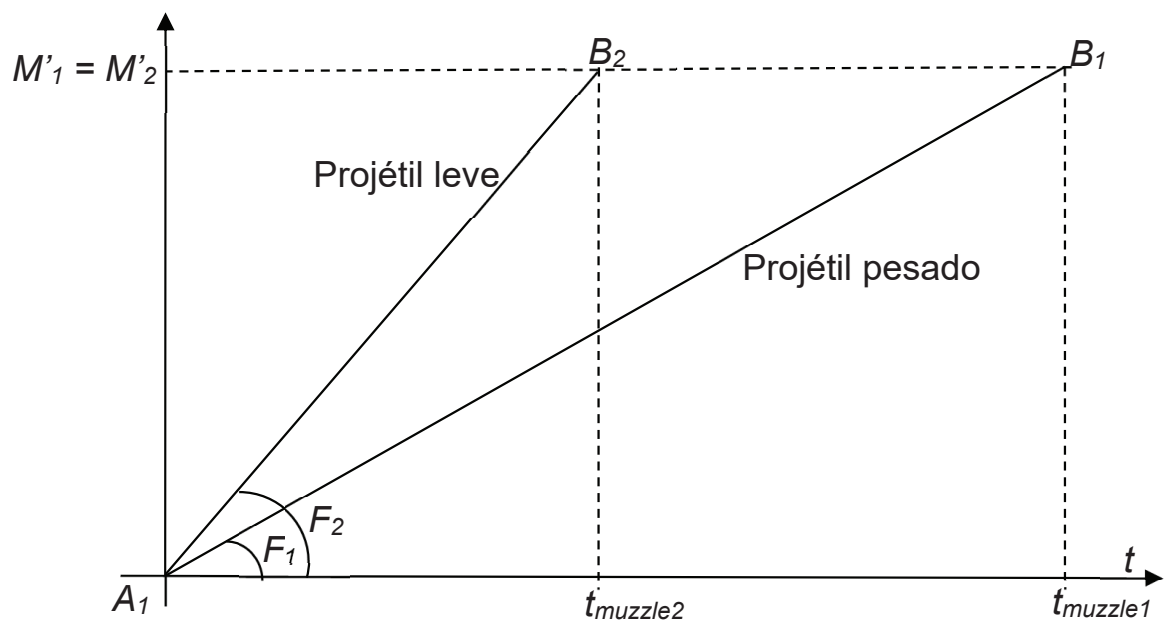

Figura 3: Variação do momento linear referente ao recuo da arma para projéteis com massas diferentes.

O projétil mais pesado é representado pela reta $A_{l} B_{l}$, cujo momento linear do projétil é igual a $M_{1}^{\prime}$ na saída do cano. Se for utilizada outra munição com um projétil mais leve, será necessário um aumento da carga de pólvora para imprimir uma maior velocidade no projétil para compensar a sua massa mais leve e atingir o mesmo momento linear $M_{1}^{\prime}$ ( ou $M_{2}^{\prime}$ ) pré-estabelecido. Ressalta-se que o aumento da carga de pólvora também levará a um aumento do momento linear dos gases; porém, tal acréscimo não é significativo em relação ao acréscimo do momento linear do projétil conforme visto na seção 4.5. O momento linear máximo será obtido em um tempo $t_{m u z z l e 2}$ inferior ao tempo $t_{\text {muzzlel }}$ do projétil mais pesado. Isso é coerente visto que com mais velocidade o projétil leve sairá do mesmo cano em um tempo menor. Assim, a reta representativa da variação do momento linear do projétil leve será a reta $A_{1} B_{2}$ do gráfico.

O gráfico mostra que para duas munições que apresentam a mesma variação de momento linear (ou de fator de potência), a que tiver projétil leve aplicará uma força $F_{2}$ maior que a do projétil pesado (força $F_{1}$ ) nas partes móveis da arma, porém o tempo de aplicação dessa força $\left(t_{\text {muzzle } 2}\right)$ será menor que a do projétil pesado $\left(t_{\text {muzzlel }}\right)$. No entanto, o impulso ou recuo da arma - ver equação (22) - será o mesmo independente da massa do projétil.

Porém, apesar do nível do recuo ser o mesmo, a forma de como esse recuo se aplica nas peças móveis da arma é diferente. Nos projéteis 
mais leves a força é mais intensa, porém por um período menor. Já com projéteis de maior massa, a intensidade da força é menor, mas é aplicada por um tempo maior.

A fim de se ter uma percepção de quão representativas são essas variações de força e tempo, pode-se realizar cálculos teóricos comparativos entre uma munição de calibre $9 \mathrm{~mm}$ Luger com um projétil de 95 grains e outra de 147 grains atirados por um cano de $117 \mathrm{~mm}$ de comprimento (especificado pela arma Glock G17), ambas com um fator de potência $\left(P F_{p}\right)$ de 128 . Isso é possível variando a quantidade de pólvora no cartucho conforme a massa do projétil a fim de obter o mesmo fator de potência.

O resumo dos cálculos comparativos encontra-se na Tabela 04 com a relação das respectivas equações utilizadas. No cálculo do tempo de percurso do projétil no cano considerou-se que a sua velocidade média de percurso equivale à metade do valor da velocidade na saída do cano, conforme a equação (28):

$$
\Delta t=\frac{\Delta s}{0,5 \times v_{\text {muzzle }}}
$$

Onde, $\Delta t$ é o tempo de percurso do projétil no cano da arma, $\Delta s$ é o comprimento do cano, e $v_{m u z z l e}$ é a velocidade do projétil na saída do cano.

Percebe-se que, aumentando a massa do projétil de 95 grains para 147 grains, consegue-se reduzir a força média do recuo em 35\%; porém, essa força se mantém aplicada por um tempo $54 \%$ superior. Ressalta-se ainda que essa diferença de tempo se encontra na fração do milissegundo, de difícil percepção a um atirador comum. Já a redução da força aplicada em 35\% é relativamente considerável. Todavia, a energia cinética da munição também é consideravelmente reduzida em $35 \%$, o que pode representar uma menor eficácia para neutralizar o oponente. 
Tabela 04: Resumo dos resultados teóricos comparativos entre munições de $9 \mathrm{~mm}$ Parabellum com mesmo fator de potência, mas com diferentes pesos de projéteis.

\begin{tabular}{|c|c|c|c|c|}
\hline & $\begin{array}{l}\text { Equação } \\
\text { utilizada }\end{array}$ & $\begin{array}{l}\text { Projétil de } \\
95 \text { grains }\end{array}$ & $\begin{array}{l}\text { Projétil de } \\
146 \text { grains }\end{array}$ & $\begin{array}{c}\text { Diferença } \\
(\%)\end{array}$ \\
\hline$m(\mathrm{em} \mathrm{kg})$ & - & 0,0061559 & 0,0094606 & \\
\hline$v($ pés/s) & $(4)$ & $1.347,3$ & 876,7 & \\
\hline$v(\mathrm{em} \mathrm{m} / \mathrm{s})$ & $(4)$ & 410,6 & 267,2 & \\
\hline$\Delta S(\mathbf{e m ~ m})$ & - & 0,117 & 0,117 & \\
\hline$t_{m u z z l e}(\mathrm{em} \mathrm{s})$ & $(29)$ & 0,00056979 & 0,000875677 & $+54 \%$ \\
\hline$F(\mathrm{em} \mathrm{N})$ & (2) & $4.436,8$ & 2887,0 & $-35,0 \%$ \\
\hline$I(\mathrm{em} \mathrm{Ns})$ & $(21)$ & 2,528 & 2,528 & \\
\hline $\begin{array}{c}F P_{p} \\
(e m \\
\left.10^{-3} \text { grain·pés } / \mathbf{s}\right)\end{array}$ & - & 128 & 128 & \\
\hline$E c$ (em Joules) & (1) & 519,1 & 337,7 & $-35,0 \%$ \\
\hline
\end{tabular}

Se comparada ao extremo com uma munição de .45 Auto com projétil de 225 grains para obter o mesmo fator de potência $\left(P F_{p}\right)$, conforme Tabela 05 , tem-se uma redução de $58 \%$ na força de recuo; porém, o tempo de duração dessa força é $137 \%$ superior ao da $9 \mathrm{~mm}$ Luger (mas ainda na fração dos milissegundos). Portanto, nessas circunstâncias, parece vantajoso o uso de projéteis mais pesados pelo atirador no aspecto de controle do recuo da arma. Todavia, nesse caso, a munição terá menor energia cinética e pode comprometer a eficácia na neutralização da ameaça, necessitando talvez a realização de mais disparos.

Tabela 05: Resumo dos resultados teóricos entre munições $9 \mathrm{~mm}$ Parabellum e .45

Auto com mesmo fator de potência, mas com diferentes pesos de projéteis.

\begin{tabular}{|c|c|c|c|c|}
\hline & $\begin{array}{c}\text { Equação } \\
\text { utilizada }\end{array}$ & $\begin{array}{c}\text { Projétil de } \\
\text { 95 grains }\end{array}$ & $\begin{array}{c}\text { Projétil de } \\
\mathbf{2 2 5} \text { grains }\end{array}$ & $\begin{array}{c}\text { Diferença } \\
\text { (\%) }\end{array}$ \\
\hline $\boldsymbol{m}(\mathbf{e m ~ k g )}$ & - & 0,0061559 & 0,014579 & \\
\hline $\boldsymbol{v}_{\text {muzzle }}(\mathbf{p e ́ s} / \mathbf{s})$ & $(4)$ & $1.347,3$ & 568,8 & \\
\hline $\boldsymbol{v}_{\text {muzzle }}(\mathrm{em} \mathrm{m} / \mathbf{s})$ & $(4)$ & 410,6 & 173,3 & \\
\hline$\Delta S(\mathbf{e m ~ m})$ & - & 0,117 & 0,117 & \\
\hline $\boldsymbol{t}_{\text {muzzle }}(\mathbf{e m ~ s )}$ & $(29)$ & 0,00056979 & 0,0013495 & $+137 \%$ \\
\hline $\boldsymbol{F}(\mathbf{e m ~ N})$ & $(2)$ & $4.436,8$ & 1873,2 & $-58 \%$ \\
\hline
\end{tabular}




\begin{tabular}{|c|c|c|c|c|}
\hline $\boldsymbol{I}(\mathbf{e m ~ N s})$ & $(21)$ & 2,528 & 2,528 & \\
\hline $\begin{array}{c}\boldsymbol{F P}_{t} \\
\left(\text { em } \mathbf{1 0}^{-3} \text { grain.pés/s) }\right.\end{array}$ & - & 128 & 128 & \\
\hline $\boldsymbol{E c}$ (em Joules) & $(1)$ & 519,1 & 219,1 & $-58 \%$ \\
\hline
\end{tabular}

Salienta-se que nestes casos o recuo seria exatamente o mesmo quando disparadas as munições, independente do calibre. Pode-se aumentar a velocidade do projétil mais pesado para obter a mesma energia cinética do projétil mais leve, todavia o recuo na arma também será maior aumentando a dificuldade de controle da arma e retomada da visada para um segundo disparo.

Porém, salienta-se também que existem limites para a variação de massa e velocidade de projétil para cada calibre de munição. Conforme Zanotta (2012), especificações técnicas dos estojos, com diâmetros corretos dos projéteis, tipo de espoleta, comprimento máximo do cartucho montado e pressão máxima da carga de pólvora são especificados pela Sporting Arms and Ammunition Manafacture Institute - SAAMI de forma a padronizar e a compatibilizar entre si os produtos de fabricantes de armas e munições. Tais especificações restringem grandes variações de massas e velocidades de projéteis dentro de um mesmo calibre, podendo ser modificados dentro de uma faixa restrita para que se mantenha a funcionalidade e a segurança do conjunto arma/munição.

\section{Representação Gráfica do Comportamento $M_{P}: V_{M U Z Z L E}: E_{C}$ DA MUNIÇÃo}

A relação entre recuo e energia cinética pode ser mais bem compreendida ao desenvolver as equações (1) e (4). Fixando um nível pré-definido de recuo $P F_{p}$ na equação $(4)$ e isolando $v_{m u z z l e}$ em relação a $m_{p}$, obtém-se a equação (29) do tipo $\mathrm{f}(\mathrm{x})=1 / \mathrm{x}$ :

$$
v_{m u z z l e}=1.000 \times \frac{P F_{p}}{m_{p}}
$$


A representação gráfica da equação (29) considerando $P F_{p}$ uma constante encontra-se na parte à direita do gráfico da Figura 4.

A equação (1) pode ser reescrita da seguinte forma:

$$
E_{c}=\frac{\left(m_{p} \times v_{\text {muzzle }}\right) \times v_{\text {muzzle }}}{2}
$$

Introduzindo a equação (4) na equação (30), obtém-se a equação (31) representada graficamente pela reta no lado esquerdo da Figura 4, considerando $P F_{p}$ uma constante:

$$
E_{c}=\frac{1000 \times P F_{p}}{2} \times v_{\text {muzzle }}
$$

O esquema mais genérico do espaço $m_{p}: v_{\text {muzzle }}: E_{c}$ encontra-se representado na Figura 5, onde pode-se ver a suas relações considerando diferentes fatores de potência $\left(P F_{p}\right)$. Tal esquema demonstra o comportamento inter-relacional entre as variáveis massa e velocidade do projétil com o recuo da arma e a energia cinética do projétil das munições.

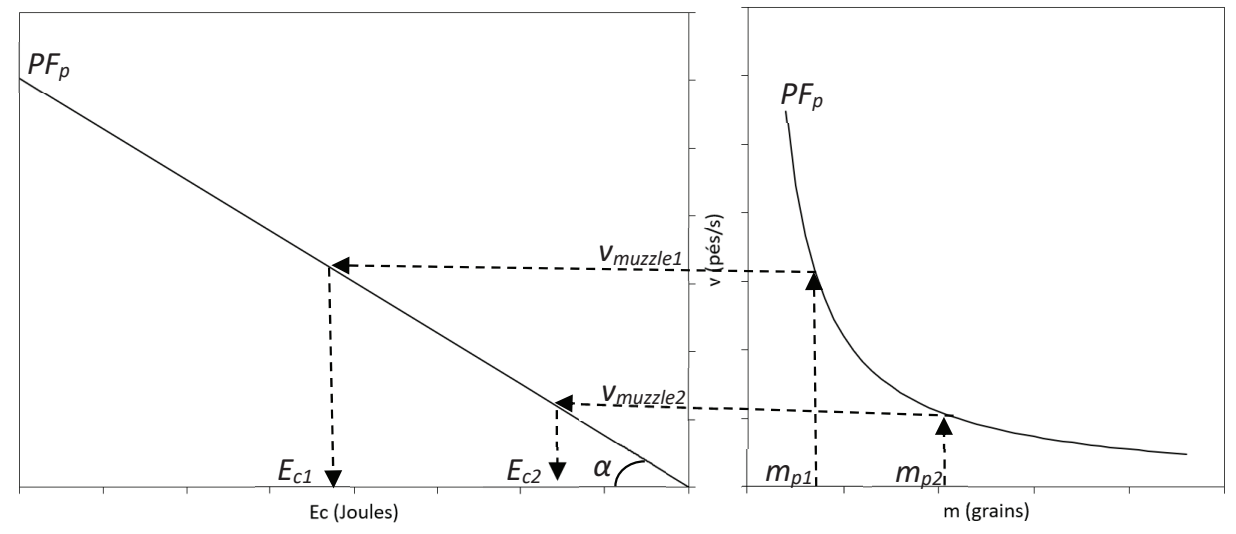

Figura 04: Esquema gráfico representando o espaço $m_{p}: v_{m u z z l e}: E_{c}$ para comparação da influência da massa do projétil em munições com mesmo fator de potência. 

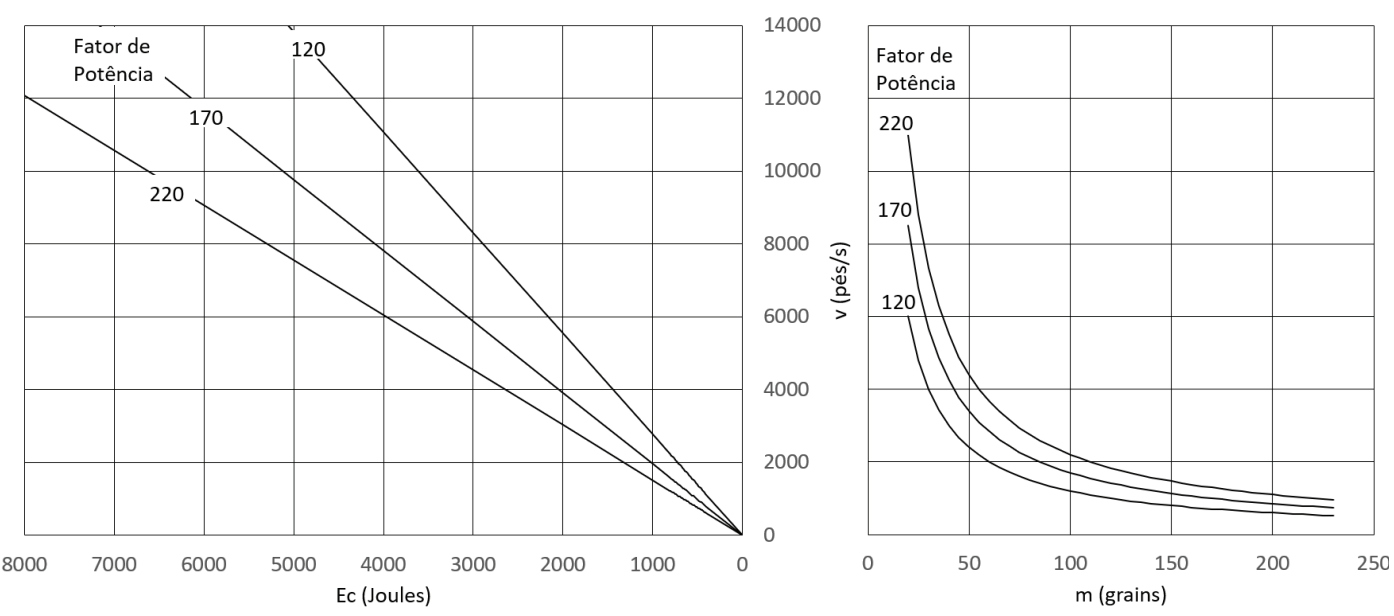

Figura 05: Esquema gráfico do espaço $m_{p}: v_{\text {muzzle }}: E_{c}$ considerando munições com diferentes fatores de potência do projétil $\left(P F_{p}\right)$.

A análise do gráfico da Figura 04 demonstra que, fixando-se um fator de potência pré-definido de valor $P F_{p}$ e escolhendo um projétil com massa $m_{p 1}$, será necessária uma certa quantidade de pólvora para que o projétil seja expelido pelo cano da arma a uma velocidade $v_{\text {muzzle }}$ para alcançar o nível de recuo $P F_{p}$, gerando por consequência uma energia cinética $E_{c 1}$. Porém, se escolher um projétil mais pesado com massa $m_{p^{2}}$ que tenha o mesmo nível de recuo do projétil com massa $m_{p 1}$, a carga de pólvora deverá ser menor para expeli-lo a uma velocidade inferior a fim de obter o mesmo fator de potência $P F_{p}$. Por consequência, a energia cinética $E_{c 2}$ resultante será menor que a munição com projétil mais leve. Por fim, a inclinação $\alpha$ da reta $E_{c}: v_{\text {muzzle }} e ́$ uma função do fator de potência definido. Percebe-se que o esquema apresentado corrobora com os exemplos anteriormente apresentados na seção 5 deste trabalho.

Importante ressaltar que a Figura 05 é na verdade um ábaco obtido matematicamente a partir da dedução de fórmulas e princípios da física clássica que descreve o comportamento das munições quanto a sua inter-relação entre massa-velocidade-energia-recuo e auxilia como uma ferramenta na escolha da munição a ser supostamente adquirida. Sabendo-se as massas $m$ em grains dos projéteis e suas respectivas velocidades $v$ em pés/s na saída do cano, pode-se comparar simultaneamente as energias cinéticas (potencial ofensivo da munição conforme a teoria da deposição da energia) e os níveis de recuo da arma (fator de potência) de duas ou mais munições testadas. 
A análise concomitante do potencial ofensivo (energia cinética) e nível de recuo da arma (fator de potência) através do ábaco da Figura 05 para diferentes munições vem de encontro ao objetivo proposto desse trabalho e, quando aplicado em estudo de caso real, por vezes revela conclusões inesperadas que sugerem certa quebra de paradigma, como será visto na seção seguinte.

\section{Aplicação em Estudo de Caso}

A Companhia Brasileira de Cartuchos - CBC é a usual (e por vezes a única) fornecedora de munições para as forças policiais brasileiras. As principais munições fabricadas pela $\mathrm{CBC}$ nos calibres $9 \mathrm{~mm}$ Luger, .40 S\&W e .45 Auto estão relacionadas na Tabela 01 de acordo com os diferentes tipos e massa de projéteis disponíveis no mercado. $\mathrm{Na}$ mesma tabela consta também a velocidade do projétil na saída da boca do cano para cada munição divulgados no site da CBC na internet, bem como os valores de energia cinética e fator de potência $\left(P F_{p}\right)$ calculados a partir dos dados publicados. Os valores constantes na Tabela 01 para cada munição foram inseridos no espaço $m_{p}: v_{m u z z l e}: E_{c}$ através dos gráficos da Figura 06. Ressalta-se que tais calibres são os normalmente utilizados em pistolas para uso policial.

Uma munição ideal seria aquela que fornecesse a maior energia com o menor recuo possível, ou seja, que estivesse o mais próximo da região do canto superior esquerdo do gráfico $E_{c}: v_{\text {muzzle }}$ da Figura 06. Os pontos extremos, como a munição .45 AUTO EXPO +P GOLD HEX 185GR e 9MM ETOG 124GR, a primeira com a maior energia (734 Joules) e a segunda com a menor energia (459 Joules) da amostra, corroboram a dificuldade de se unir estas características na mesma munição. A munição 45 AUTO EXPO + P GOLD HEX 185GR com a sua alta energia acaba tendo um recuo maior inerente $\left(F P_{p}=212\right)$, enquanto a munição 9MM ETOG $124 \mathrm{GR}$ consegue ter um recuo muito inferior $\left(F P_{p}=138\right)$, mas trazendo consigo uma energia cinética também muito inferior.

Como é difícil ter as características de maior potência e menor recuo na mesma munição, talvez seja interessante observar as munições entre os calibres estudados que tenham um equilíbrio dessas ca- 
racterísticas, estas situadas na região central do gráfico $E_{i}: v_{\text {muzzle }}$ da Figura 06, ou seja, com fator de potência em torno de 160 e energia cinética em torno de 600 Joules. As munições $9 \mathrm{MM}$ EXPO +P+ BONDED 115GR e .40 S\&W CXPO COPPER BULLET TACTICAL apresentam tais características e talvez sejam as que melhor combinam um equilíbrio entre nível de recuo e energia cinética dentre as munições fornecidas pela CBC para os calibres $9 \mathrm{~mm}$ Luger, $.40 \mathrm{~S} \& \mathrm{~W}$ e .45 Auto.

A comparação entre as munições .45 AUTO +P COPPER BULLET TACTICAL, .45 AUTO CSCV 200GR e .45 AUTO ETOG 230GR através da Tabela 01 e da Figura 06 demonstra que elas possuem o mesmo nível de recuo $\left(P F_{p}\right.$ em torno de 190), porém suas energias variam de 485 Joules (para a tipo ETOG) até 655 Joules (para a tipo COPPER BULLET) devido à variação da massa do projétil, similar ao exemplo teórico apresentado na Tabela 04 da seção 5, mostrando no caso prático a influência da massa do projétil na energia e no nível de recuo da arma proporcionado pela munição. Obviamente, por terem o mesmo recuo, a munição do tipo COPPER BULLET apresenta-se a priori como a melhor opção entre as três para uso em autodefesa por ter maior energia cinética (quando considerados apenas os critérios de energia e de recuo para a escolha).

Existe também um pensamento intuitivo que quanto maior o calibre, maior será a sua energia cinética e o seu recuo. Esse paradigma nem sempre é verdadeiro conforme os dados constantes no gráfico $E_{i}$ :$v_{\text {muzzle }}$ da Figura 06 e na Tabela 01. Por exemplo, comparando-se a munição 45 AUTO ETOG 230GR com a munição 9MM EXPO +P+ BONDED 115GR percebe-se nesse caso que a munição no calibre 9 $\mathrm{mm}$ Luger possui maior energia cinética e menor recuo que a munição .45 Auto, o que inicialmente parece contraintuitivo (imagina-se que o calibre .45 Auto tenha sempre energia e recuo muito superior ao 9 $\mathrm{mm}$ Luger). O motivo é que a munição no calibre .45 Auto em questão impulsiona um projétil de grande massa a baixa velocidade, enquanto a munição $9 \mathrm{~mm}$ Luger o contrário, um projétil leve a maiores velocidades relativas. Como a energia cinética é proporcional ao quadrado da velocidade, a munição $9 \mathrm{~mm}$ Luger consegue alcançar maior energia que as munições mais fracas em .45 Auto (611 Joules para o $9 \mathrm{~mm} \mathrm{Lu}$ ger contra 485 Joules para .45 Auto) mesmo apresentando um menor nível de recuo $\left(P F_{p}=152,8\right.$ para a munição $9 \mathrm{~mm}$ Luger enquanto $P F_{p}$ 
$=192,5$ para o calibre .45 Auto). Outro caso interessante é entre as munições .40 TREINA 160GR e .45 AUTO +P COPPER BULLET TACTICAL que, apesar de serem de calibres diferentes, são praticamente equivalentes apresentando massas, velocidades, energias e nível de recuo muito próximos. Isso desmitifica a ideia de que o calibre maior sempre proporcionará maior energia e maior recuo em relação ao calibre menor.

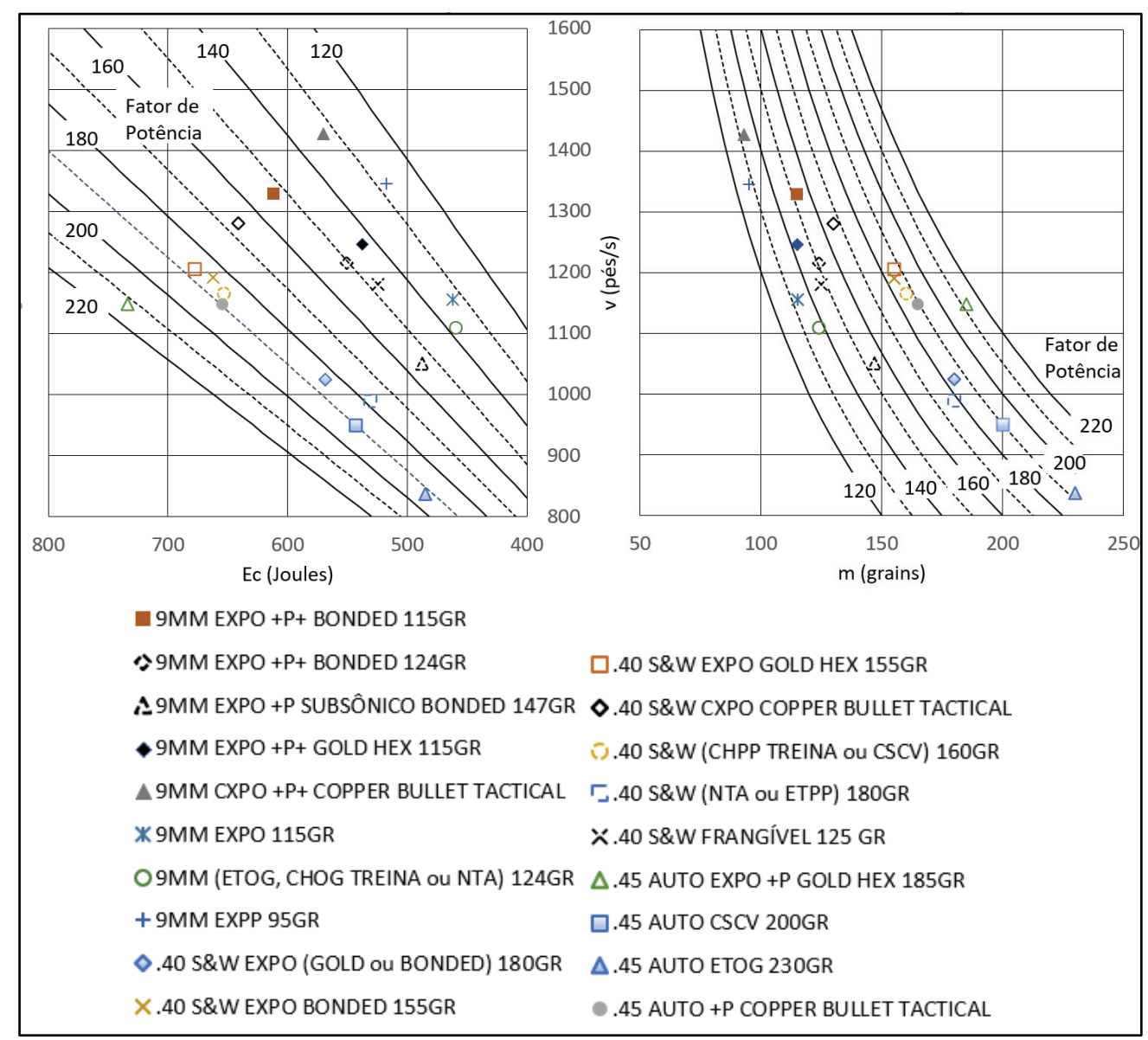

Figura 06: Gráficos representativos do espaço $m_{p}: v_{m u z z l e}: E_{c}$ das principais munições fabricadas pela CBC em calibre $9 \mathrm{~mm}$ Luger, $.40 \mathrm{~S} \& \mathrm{~W}$ e .45 Auto.

Existem diversos critérios usualmente adotados para escolha de munição para fins policial, como energia cinética, velocidade do projétil, massa do projétil, nível de penetração, deformabilidade do projétil, integridade do projétil em desvio de trajetória, precisão, entre tantos outros. Porém, normalmente não há a adoção de critérios específicos para avaliar o recuo da arma causado pela deflagração da munição, ficando restrito apenas na escolha do calibre, seguindo a intuição que 
calibres maiores provocam recuos maiores (o que foi demonstrado que não é necessariamente verdadeiro).

Portanto, a aplicação dos estudos teóricos nos exemplos reais demonstra a utilidade do uso do nível de recuo calculado pelo fator de potência como um dos parâmetros para a escolha da munição para fins policial.

\section{Conclusốes}

O conceito de fator de potência utilizado nas modalidades desportivas do Tiro Prático, regulamentados internacionalmente pela International Practical Shooting Confederation - IPSC, é uma forma conhecida e eficiente de medir o nível de recuo da arma causado pela deflagração de uma determinada munição e pode ser utilizado como um dos critérios de escolha da munição para uso policial.

O nível de recuo da arma durante o disparo está vinculado diretamente ao fator de potência da munição, ou seja, quanto maior o fator de potência da munição, mais recuo ela causará na arma.

Munições com mesmo fator de potência terão o mesmo recuo, independente de terem projéteis mais leves ou mais pesados. Porém, a aplicação da força desse recuo será diferente. Projéteis mais leves resultarão na aplicação de uma força mais intensa e por um período menor, como se fosse uma "pancada", enquanto nos projéteis pesados a força será de menor intensidade e por um período mais longo, algo como um “empurrão”.

Cálculos teóricos indicaram que, para munições com um mesmo fator de potência, o uso de projéteis mais pesados daria condições para o atirador melhor controlar o recuo da arma. Porém, nessas condições, os projéteis mais pesados também teriam menor energia cinética, diminuindo o nível de eficácia na neutralização da ameaça e talvez obrigando o agente de segurança pública a realizar mais disparos para cessar a agressão. 
Uma munição disparada que proporciona maior energia cinética não significa necessariamente que ela também proporciona maior recuo da arma, e vice-versa.

O desenvolvimento matemático das fórmulas e dos princípios da física clássica apresentado neste trabalho resultou na elaboração de dois ábacos (Figura 05) que demonstram o comportamento inter-relacional entre as variáveis massa e velocidade do projétil com o recuo da arma e a energia cinética do projétil. Nesses ábacos foi utilizado o fator de potência como medida do nível de recuo da arma.

Métodos já internacionalmente utilizados para análise e avaliação de munições, como os protocolos do Federal Bureau of Investigation - FBI, poder de parada (stopping power) e teoria da deposição da energia cinética (kinetic energy deposition theory), focam praticamente só nos efeitos do projétil no alvo para seleção da melhor munição, negligenciando ou tratando em segundo plano os efeitos no recuo da arma. Porém, o uso dos ábacos da Figura 5 permite incluir simultaneamente os efeitos da munição no alvo (energia cinética) e no recuo da arma (fator de potência) na análise comparativa entre munições.

Estudo de caso utilizando dados balísticos publicados pela Companhia Brasileira de Cartuchos - CBC para suas munições de calibre $.9 \mathrm{~mm}$ Luger, $.40 \mathrm{~S} \& \mathrm{~W}$ e .45 Auto, os quais são os principais calibres para pistolas de uso policial, foi apresentado demonstrando a aplicabilidade dos ábacos da Figura 5 e corroborando com as conclusões da análise teórica anteriormente apresentadas.

O trabalho também sugere incluir nos critérios de avaliação de compra de munições pela Administração Pública para uso policial o nível de recuo (fator de potência) que cada munição ofertada proporciona na arma.

Por fim, espera-se que as conclusões alcançadas neste trabalho possam subsidiar a Administração Pública na ampliação dos critérios discutidos referente às especificações técnicas para compra de munições para uso policial. 
Giovani Vilnei Rotta

Doutorado em Engenharia Civil

Universidade Federal do Rio Grande do Sul

Polícia Federal - PR

José Antonio da Silveira Júnior

Mestrando em Políticas Públicas e Desenvolvimento

Universidade Federal da Integração Latino-Americana

Capitão da Polícia Militar do Paraná

\title{
The Effects for Police Use of The Variation of the Mass and Velocity of The Projectile IN THE Kinetic ENERgY OF THE AmMUNition AND IN THE RECOIL OF THE FIREARM
}

\begin{abstract}
The methods internationally used in the analysis and evaluation of ammunition for police use mainly consider the possible effects caused by the projectile on the target, abdicating the adverse effects of the retreat of the weapon caused by the ammunition, such as the increased difficulty of the control of the weapon by the police during a sequence of shots. The present study searches to fill this gap by proposing the inclusion of the power factor as one of the variables to be analyzed for the choice of ammunition. For this, a mathematical deduction work was carried out based on classical physics formulas and principles to demonstrate the interrelational behavior between the mass and velocity variables of the projectile with the recoil of the weapon and the projectile kinetic energy.

Finally, a case study is also presented using ballistic data from various ammunition manufactured by CBC in the $9 \mathrm{~mm}$ Luger, $.40 \mathrm{~S} \& \mathrm{~W}$ and .45 Auto calibers to demonstrate the power factor applicability.

Finally, a case study is also presented using various ammunition manufactured by CBC in calibers $9 \mathrm{~mm}$ Luger, $.40 \mathrm{~S} \& \mathrm{WW}$ and .45 Auto to demonstrate the power factor applicability.
\end{abstract}

KEYWORDS: Ammunition. Recoil of the weapon. Kinetic energy. Power factor. Newton's laws. 


\title{
Los Efectos para el Uso Policial de la Variación de la Masa y Velocidad del Proyectil en la Energía Cinética de la Munición y en el Retroceso del Arma de FUEGO
}

\begin{abstract}
RESUMEN
Los métodos internacionalmente utilizados en el análisis y evaluación de municiones para uso policial consideran únicamente los posibles efectos que ocasiona el proyectil sobre el blanco, abdicando de los efectos adversos del retroceso del arma provocados por las municiones, como el aumento de la dificultad de controlando el arma por parte de la policía durante una secuencia de disparos.

El presente estudio busca llenar este vacío proponiendo la inclusión del factor de potencia en la evaluación técnica de municiones. Para ello, se llevó a cabo un trabajo de deducción matemática basado en fórmulas y principios de la Física Clásica para demostrar el comportamiento interrelación entre las variables de masa y velocidad del proyectil con el retroceso del arma y la energía cinética del proyectil.

Los resultados mostraron que el factor de potencia es una forma eficiente de medir el nivel de retroceso del arma transmitido por la deflagración de una munición suministrada y puede utilizarse como uno de los criterios para elegir munición para uso policial. Finalmente, también se presenta un estudio de caso utilizando datos balísticos de varias municiones fabricadas por CBC en los calibres $9 \mathrm{~mm}$ Luger, .40 S\&W y .45 Auto para demostrar la aplicabilidad del factor de potencia.
\end{abstract}

Palabras Clave: Municiones. Retroceso del arma. Energía cinética. Factor de potencia. Leyes de Newton.

\section{REFERÊNCIAS}

BRASIL. Lei $n^{\circ}$ 10.826, de 22 de dezembro de 2003. Dispõe sobre registro, posse e comercialização de armas de fogo e munição, sobre o Sistema Nacional de Armas - Sinarm, define crimes e dá outras providências.

BRASIL. Decreto $n^{\circ} 9.847$, de 25 de junho de 2019. Regulamenta a Lei n. ${ }^{\circ} 10.826$, de 22 de dezembro de 2003, para dispor sobre a aquisição, o cadastro, o registro, o porte e a comercialização de armas 
de fogo e de munição e sobre o Sistema Nacional de Armas e o Sistema de Gerenciamento Militar de Armas.

BRASIL. Decreto $n^{\circ} 10.030$, de 30 de setembro de 2019. Aprova o Regulamento de Produtos Controlados.

CARLUCCI, Donald. E.; JACOBSON, Sidney S. Ballistics: theory and design of guns and ammunition. 3. ed. Boca Raton, USA: Taylor \& Francis, 2018.

CHEVALIER, Bill. The ABC's of reloading: the definitive guide for novice to expert. 8.ed. Iola, USA:Gun Digest Books, 2008.

COMPANHIA BRASILEIRA DE CARTUCHOS. Munições para armas curtas. Disponível em: https://www.cbc.com.br/produtos/ categoria/municoes-para-armas-curtas/linha/municoes-parapistolas/. Acesso em: 09 jul. 2020.

DALTON T. BROWN, Inc. Ballistics Assessment - FBI Test Protocols. Disponível em: http://www.dtbtest.com/eLibrary/ ballistics-FBI-protocol.pdf. Acesso em: 16 fev. 2021.

ELLIFRITZ, Greg. An alternative look at hadgun stopping power. Buckeye Firearms Association, 2011. Disponível em: https://www. buckeyefirearms.org/alternate-look-handgun-stopping-power . Acesso em: 31 mar. 2020.

FEDERAL AMMUNITION. Gold Medal Handgun 38 Special. Disponível em: https://www.federalpremium.com/handgun/goldmedal/gold-medal-handgun/11-GM38A.html> . Acesso em: 20 mar. 2020.

GERMERSHAUSEN, R. et al. Handbook on Weaponry. $1^{\text {st }}$ English ed. Düsseldorf, Germany: Rheinmetall GmbH, 1982.

MARSHALL, Evan. P.; SANOW, Edwin. J. Handgun Stopping Power: The Definitive Study. Boulder, USA: Paladium Press. 1992. International Practical Shooting Confederation (IPSC). Handgun Competition Rules. January, 2019 ed. Mallorca, Spain. Disponível em: https://www.ipsc.org/ipsc-rules/rule-books/ Acesso em: 13 fev. 2020 . 
OLIVEIRA, João Alexandre Voss de; GOMES, Gerson Dias; FLORES, Erico Marcelo. Tiro de Combate Policial, uma abordagem técnica. 4.ed. Erechim: Gráfica e Editora São Cristovão, 2001. RESNICK, Robert.; HALLIDAY, David. Física 1. 4.ed. Rio de Janeiro: Livros Técnicos e Científicos Editora, 1984.

WOOD, Mike. Ballistic gelatina comparrisons: Part I. Publicado na Plataforma Police1, 11/2019. Disponível em https://www.police1. com/police-products/firearms/accessories/ammunition/articles/ ballistic-gelatin-comparisons-part-i-ndmFBGUHw79F9s0a/ Acesso em: 16 fev. 2021.

ZANOTTA, Crezo M. Manual de Recarga de Muniçôes. Ed. Especial $\mathrm{n}^{\circ}$ 44. Revista Magnum. São Paulo: Sicurezza Editora, 2012. 


\section{SOBRe a Revista}

Formato: $16 \times 24 \mathrm{~cm}$

Mancha: $37 \mathrm{p} 9,543 \times 54 \mathrm{p} 3,969$

Tipologia:

Várias

Papel:

Offset $75 \mathrm{~g} / \mathrm{m}^{2}$ (miolo)

Supremo $250 \mathrm{~g} / \mathrm{m}^{2}$ (capa)

Vol. 12 n. 5, maio/ago. 2021.

Equipe de Realização

Projeto Editorial

Coordenação Escola Superior de Polícia

Edição de Texto

Stenio Santos Sousa

Editoração

Daniel Marcos Gomes

Gleydiston Rocha

Normalização

Sônia Luiza de Oliveira

Virgílio Vieira de Melo Junior

Revisão

Carlos Alberto Venâncio de Sousa

Paulo Edson Castro

Viviane Matos Teixeira

Impressão e Encadernação

EQUIPE Nugraf/SPP/CESP/ANP

ACADEMIA NACIONAL DE POLÍCIA

Coordenação Escola Superior de Polícia 